\title{
Short Review of QCC (Quality Control Circle) Implementation toward Productivity Improvement: Case Study
}

\author{
${ }^{1}$ Zubaidi Faiesal Bin Mohamad Rafaai \\ ${ }^{1}$ Mechanical Engineering Department, \\ College of Engineering \\ Universiti Tenaga Nasional, Jalan IKRAM-UNITEN \\ 43000 Kajang, Selangor, Malaysia
}

\author{
${ }^{2}$ Amir Hamzah Bin Abdul Rasib \\ ${ }^{2}$ Manufacturing Engineering Technology Department, \\ Universiti Teknikal Malaysia Melaka, \\ Melaka, Malaysia
}

\author{
${ }^{3}$ Yusri Bin Ishak \\ ${ }^{3}$ Quality Assurance Department, \\ Samsung Electronics (M) Sdn Bhd \\ Lot 2, Lebuh 2, North Klang Straits, 41000 Port Klang, \\ Selangor, Malaysia
}

\begin{abstract}
This paper will review on the implementation of Quality Control Circle in an organization that can improved productivity of the organization. Focus more on effect of Quality Control Circle implementation, process of implementation and factors that help to improve productivity to meet customer demand. A few case studies conducted to review the quality circle method implementation. Comparison of different organization conducted in order to understand the implementation of QCC in their work area.
\end{abstract}

Keywords - Quality circle, Implementation, Organization, Objective, Benefits, Factors

\section{INTRODUCTION}

Quality circle (QC) or sometimes Quality Control Circle (QCC) defined as a method that encourages a group involvement in problem solving activities in order to enhance the productivity. These group activities can include any number of employees ranging from various levels in the working hierarchy of an organization. A successfully established quality circle eventually will boost the morality of the participants. The achievement that achieved as an overall makes them feel motivated to play their role in the organization.

Some of the companies that have exceled under the guidance of leaders who practice the concept of QC are Toyota, Nippon Wireless and Telegraph Company [1]. The QC method have helped to improve the quality of the product and services, which provided by those company. QCC activities has instils cooperation and communication among fellow workers and makes them feel that they too are important to the company

In an industry, specifically manufacturing industry, which involves with labor, input, process and output, has to maintain or increase in term of the quality and productivity of their industry. Quality is ability of product to satisfy the customer's requirement. Quality control circle (QCC) is a method to observe, analyze, evaluate and solve the problem faced by a manufacturing industry in maintaining or increasing quality and production of their product.

Quality control circle (QCC) helps an industry to identify the problem in maintaining the quality. QCC also provides solution for the problem through sorting, survey and experimenting. The solution of the identified problem will based on the result that QCC's member obtained. QCC implements the solution and verify it. The quality circle usually consists of six basic elements, which are 1) Top management, 2) Steering committee, 3) Co-coordinator, 4) Leader, 5) Members, and 6) non-members [2].

\section{OBJECTIVE \& STRUCTURE}

The ultimate objective of QC is to contribute to company development, which respect to human relations. This will create a satisfactory working environment that can enhance the productivity of an organization. Quality circle targets the development of human relationships and communication among individuals to raise their awareness of the responsibilities in relation with the products delivered. Besides that, QC aims to create a framework where improvement ideas transformed to an actual application. This will also develop inner leadership and employees' responsibilities to the organization [3]. In general, the organizational structure of quality circle generally consists of six levels such as members, nonmember, leader, facilitator, steering committee and top management.

QC Members: Members of a single work group voluntarily form a circle, which they can withdraw from the circle if they wish to do so. Normally, members are 
encouraged to attend meetings regularly, participate actively and share ideas related to problem solving.

QC Leader: An elected leader will coordinate and supervise the work of each quality circle members. The QC leader will motivate members to participate actively and acts as a bridge that link between members and the facilitator. Besides that, the leader also trains members to identify problems and apply problem-solving techniques.

Facilitator: The quality circle and the steering committee will be mentor by the facilitator. Facilitator initiates the setting up of QCs by persuading the supervisor and evaluates the QC operations and programmes. Other than that, the facilitator needs to provide review and feedback to steering committee about the proceedings and results of the QC.

Steering Committee: This committee consists of top-level management from different departments and employee's union. This committee will sponsor QC programme for the whole organization by defining overall objectives and operating guidelines to identify which department where the circles to be formed. They also select and train the facilitators and provide the resources to the facilitator [4].

For the application of Quality Circle, there are seven steps to make Quality Circle is a successful one. First step is to identify the problem, which will be done by the Quality Circle members. The problem is identified by the members, which the purpose is to solve it. Next, problems are analysed and try to solve it by using main problemsolving approach. Thirdly, come out with backup plans that focus more on various options of solutions. The solutions are generated to fully encounter for upcoming problems that may be happened.

After that, the outstanding solutions among them are chosen as the main solution. The most outstanding solution is based on which solution that is most suitable for the problems encountered. The fifth step is preparing an action plan for the solutions. The Quality of Circle members planned for the implementation of solution such as time, date and venue. Before the implementation of the solution, it will be presented to the management in order to obtain the approval. End of the step is the management appraise the solutions and approve it to be tested for small scale in order to check its reliability. See Figure 1 for the working model of Quality Circle. [7].

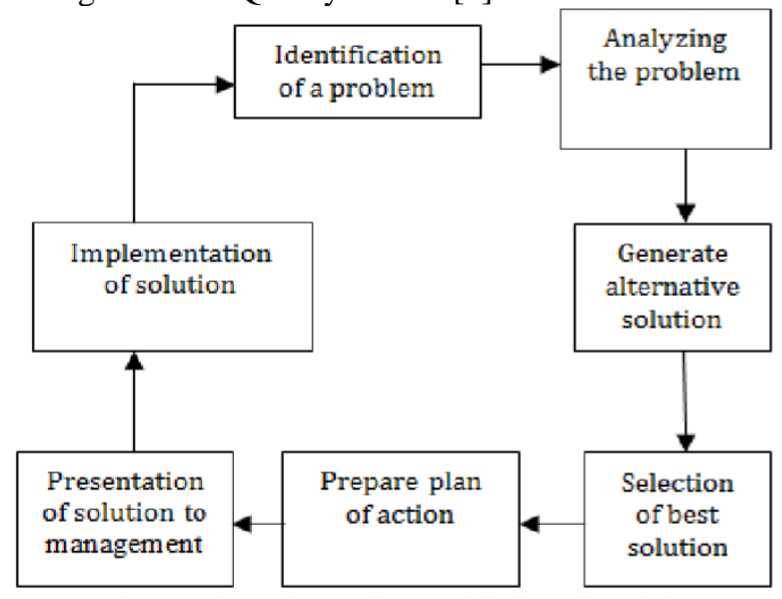

Figure 1 shows the working model of Quality Circle

\section{PRO \& CONS}

A research journal had conducted a study regarding the practise of quality control circle (QCC) in an organization and the significant impacts it has on the employees' productivity and to the overall productivity of the organization itself. The concept of QC approached variously by different organizations. The management's approach towards QC is to ensure that all responsible department in an organization work together in order to improve and maintain the quality of their product/services.

QCC programmes conducted in organizations encourage group participation employees and can only succeed depending on how well each member work and communicate with one another. The study found that QCC participants eventually ended up with a positive attitude approach towards their role in the organization. Positive thinking members were able to possess better decision making and problem-solving ability and also sharpen their skills which reduced the cases of skill related mistakes and thus improving the overall productivity of the individual and also the organization itself. Table 1 show the significant impact of practising QCC has on the employees [5].

Table 1: Comparison between QCC members and NonQCC members

\begin{tabular}{|c|c|c|c|}
\hline No & Factors & $\begin{array}{c}\text { QCC } \\
\text { Member (in } \\
\text { \%) }\end{array}$ & $\begin{array}{c}\text { Non QCC } \\
\text { Member (in } \\
\text { \%) }\end{array}$ \\
\hline 1 & Job satisfaction & 72 & 28 \\
\hline 2 & $\begin{array}{c}\text { Willing to expand } \\
\text { effort for achieving } \\
\text { organization goal }\end{array}$ & 68 & 32 \\
\hline 3 & No intention to quit & 80 & 20 \\
\hline
\end{tabular}

The various advantage of establishing QCC in an organization are aiding workers to have a positive view on their role for the organization, enhancing productivity by improving the quality of the product and reducing the amount of rejected product. QCC also build up strong bonds between various employees from various level of the working hieracy, improve the working conditons and working environment. By the end of the activities conducted in the team, indirectly help employees in their self and social development skills.

However, there are some disadvantages of implementing QCC, which are the organization will require more time and money in order to build a successful QCC, the organization's weakness will be exposed, and effective results can only be clearly seen if conducted on large organizations. Most of the current difficulties faced in establishing QCC are that the organization will require a large number of trained staff, most employees will not be voluntary participate in QCC based activities, people in higher levels of the working hieracy will be dissapointed as they will be expecting quick and effective results and buidling a mutual relationship is difficult and will take time as each participant will have their own thoughts, views, ego and approach towards a situation [6].

There are several factors that affecting the implementation of the Quality Control Circle. First, the lack involvement and commitment of board and top 
management into the exposure of the activities in Quality Control Circle to the members in conjunction with other organisation target and goals. It is because a successful organisation depends on the level of maturity in terms of leadership and commitment of the leading people in the organisation. Next, strategic planning of an organisation is crucial in order to achieve vision and mission of an organisation as it contributes to a suitable judgement that can assess an organisation current performance. This planning also included risk management planning which prepare backup plans that can investigate and handle the risks. The organisation mission also has to be in same direction of organisation goals and target which transform into operation planning.

Apart from that, communication is one of the significant aspects to have a sustain organisation. Communication absence will affect the organisation efficiency to the lowest as it leads to lack of involvement from the employee. Each department should have good communication system each other to get information, which results in maintaining the organisation capability. As the organisation is dealing with human being, motivation and moral support are needed to ensure their moral are in tiptop condition. Incentives such as bonus, facilities improvement and family day should be given as a reward of their hard work working to the organisation [7].

In order to have a sustainability of an organisation, endless of improvement have to be done to maintain the effectiveness of the organisation. This aspect is where maintenance team will apply their maintenance planning towards a better organisation. This factor is vital if an organisation wants a better-quality management system present and in future. In recent technological development, research and development must have continuous improvement if the organisation wants to compete in recent industry market. The organisation must have steps ahead of its competitors, which focus more on innovation and development of existing technology.

\section{CASE STUDY}

Below are short reviews for comparison of QCC implement in several of the company.

\section{A. Quality Circles in Open and Distance Learning Institutions; Opportunities and Challenges: A Case of the Zimbabwe Open University [8]}

Student's quality circle is the one of the examples to make sure the continuous improvement in either teaching or learning. Quality Circle consists of two basic management principles. Firstly, for the people experienced the effect of the decision should be contribute in making it. Secondly, the individual who experienced the situation have the greatest incentive and potential to improve it. Quality Circle is made up of two or more of students from the same group. They collect and analyze the problem they face. Identifying the root cause and then come up with the solution. Furthermore, Quality Circle maximizes quality control concepts, tools and technique for solving the problems.
There are various of benefits in this sector such as benefits of Quality Circle, benefits to the University, benefits to the Circle members, benefits to the Circle leaders and benefits for facilitators.

\section{B. Quality Circle to Improve Productivity: A Case Study in a Medium Scale Aluminium Coating Industry [9]}

There are two types of industry, which is small and medium scale. Moreover, there are problems that will improve the quality, productivity, safety delivery time of their products and services when solved. Two names were called in some countries originated in Japan in year 1962 , which is The Quality Circles (QCs) or Quality Control Circles (QCCs). They originally consist of forming groups of workers, which in common 8 to 12 working in similar areas to solve the problems via systematic approach. Hence, Quality Circle is a small group of employees doing similar work on shop floor, who voluntarily meet together on a regular basis to identify problems and suggest improvements in their respective work areas on shop floor.

The objectives of Quality Circles are a beautiful blend of individual and organizational objectives. They include change in attitude, self and mutual development that is development of team spirit, improvement in organizational culture as much as improving the productivity and performance of the organization.

\section{The Effectiveness of Quality Circle Participation in Industrial and Service Organizations in Malaysia [10]}

In 2005, an assessment was done to resolve whether Quality Control Circle (QCC) done in service sector is better than in industry sector. Theoretically, QCC is like a supplement for blue collar workers than white collar workers. This research was done by distributing questionnaire. The questionnaire was mailed to several companies selected from National Productivity Cooperation (NPC) record to be answered by QCs members and non-members of each companies. 130 questionnaires were returned out of 300 distributed. The structure of the survey was extracted from Crocker (1984) in her previous study. There are five parts of the survey form which are technical aspects of QC, QC process, effectiveness of organization and employee contribution to the QC, QC and organization and background of the respondents. All these data were later scrutinized by using Bivariate Correlations and one - way ANOVA.

The outcomes of this paper were industrial QCs displayed an enthusiastic behaviour than service QCs members. The industrial members held more meeting comparing to service members per month. Next, $66 \%$ of the QCs in service division had more experience comparing to $66 \%$ QCs in manufacturing division which may explain the keenness to held meeting less frequent. However, there are no notable contrast that both sectors have improved in term of problem solving skills. Service QC members feel that they have contributed something and improved their organizations financial status compares to industry QC members. Furthermore, the industry QC members have reported to refine their communication and relationship 
between colleague compare to their service counterparts by enrolling to this QC program.

Generally, it can be inferred that both service and industrial QCs have agreed that their companies and their works were fine. However, only service group is willing to increase their hard work towards company values and goals. The industry group is relatively younger than the other, which explain the great impact of QC program on the outcomes and attitude of the group. Finally, industrial QCs are keener than service QCs in terms of participation in QCs programs. Never the less, QCs in service is much aware of their offering towards companies financial than the other.

\section{The Effects of Quality Control Circle on Employee Perceptions and Attitudes in Selected Companies: Kingdom of Bahrain [11]}

The study is regarding the outcome of quality control on Nestle Waters' workers' perceptive and behaviour. Descriptive research along with method like questionnaire, unstructured interviews, and documentary analysis were done in this research. For the questionnaire there are five parts which are technical portion of the QCC, QCC procedure, successfulness of the circle, general perception of QCC and company and finally respondents' background. Statistical treatment was applied to analyse the data and answer the questions about the relationship of training adequacy to QC effectiveness and leadership in QCC. It was founded that training is helpful for everyone in the company to comprehend the importance of QCC.

Next, the employees gave satisfactory responses towards the QCC and company, thus proving their enthusiasm and willingness to put extra effort for the QCC. Third, the respondents realise the vitality of employees' happiness and satisfaction about their job as it helps company to achieve their goals and values. The respondents appreciate that they are identified in the goal and values of the company. Finally, it can be deduced that the employees now believe that everyone is important. Everybody is contributing something to the company in order to achieve company's targets. Company should enhance the effort towards this programs that will increase staffs' commitment and job satisfaction as well as devise rewards program to further motivate it members.

\section{E. Quality Improvement Application in Lumber Industry \\ Timber Production [12]}

Based on the research, there are seven different types of basic principles of quality control circle, which are arrangement chart, causality diagram, histogram, control chart, dispersion pattern and deamination. There are several factors, which affects the lumber quality, grasp key aspects, about the improvement timber production quality and increase the production of the timber and its quality. A forestry bureau was been formed to solve the problem of work, which named as "eagle-eyed group".

The group consists of a QCC leader, a group leader, an instructor. Data group, analysis group, general affairs group and document group works under the QCC leader. There were six factors affecting the timber production which are weak bucking, weak management of forest resource, staff works level, weak management of electromechanical device, environment workplace and production technical guidance. The six factors were sorted based on a survey. Based on the sorting two main factors has the highest score which are weak bucking and the weak management of forest resources. For the weak management of forest resources, the forestry unit has found bad resource management phenomena based on survey. The forestry unit has found main problem for weak bucking through massive $\log$ investigation. There are few solution for solve the problem of the weak management of forest resource which are make a target, appoint a person to verify the cutting area, cutting number and registration, and formulate pick the logging name plate system. For the weak bucking, the forestry unit has identify few solution to overcome the problem which are the staffs should be well trained, the staffs have to observe certain criteria before design the lumber and use the high quality timbers. In conclusion, the QCC has improved on the two main factors, which was affecting the quality and production of the timber.

Quality Control Circle (QCC) has being applied to various industries to improve quality and productivity through different technique of identifying problems and generating alternatives. It can be concluded the QCC method is a very efficient to be implement in the industries to improve the quality and productivity. The method is simple but very effective since it does not require a high level of technological facilities or managerial abilities or financial investment. However, to use this approach, it need high teamwork and cooperation because one of the reason the quality circle method fail to be implement is because of poor teamwork. This failure can be eliminate through bonding and team building among the team

\section{SUMMARY}

Quality circle programs are very simple. It does not overlap company structures. They are adapted to each problem that appears. The biggest challenges appear at middle level where there is fear for lack of justification of authority. Quality circles do not undermine decisionmaking hierarchy in a company because they are work groups, creative and solution oriented, trying to find solutions to improve quality. They strengthen the structure of an organization, enriching and humanizing work, giving decision-making power to lower levels.

In this way, employees become more responsible, more careful and more involved in work when they feel appreciated thus increasing work productivity. The success of the quality circle movement is definitely a collective effort and involvement of both the management and employees.

\section{REFERENCES}

[1] "Quality circle", En.wikipedia.org, 2018. [Online]. Available: https://en.wikipedia.org/wiki/Quality_circle. [Accessed: 26- Aug2018].

[2] F. Talib and M. Ali, "Impact of Quality Circle-a Case Study," International Engineering, vol. 84, 2003.

[3] B. J. Petruta Blaga, "Human Resources, Quality Circles, Innovation," Procedia Economics and Finances, vol. 15, pp. 1458$1462,2014$. 
[4] C. H. Kalpana Koneru, "Understanding and Managing Quality Circles: a Theoretical Perspective," International Journal of Research in Management Issues, vol. 1, no. 1, pp. 24-33, September 2013.

[5] Y M. Chaudhary, "Impact of Quality Circle Towards Employees \& Organization A CASE STUDY", IOSR Journal of Engineering, vol. 02, no. 10, pp. 23-29, 2012.

[6] N. Shireen, "Quality Circle: A Fundamental Unit of Increase Profitability", International Journal of Management and Commerce Innovations, vol. 2, pp. 30-34, 2018.

[7] R. Sourabh and R. Chaudhary, "Quality Circle in Organization and its Implementation", International Journal of Current Engineering and Technology, vol. 6, no. 3, p. 889, 2016.

[8] T. Nyenya and G. Rupande, "Quality Circles in Open and Distance Learning Institutions; Opportunities and Challenges: A Case of the Zimbabwe Open University", International Journal of Innovative Research and Development, vol. 3, no. 6, pp. 539-546, 2014.

[9] S. Kulkarni, S. Welekar and A. Kedar, "QUALITY CIRCLE TO IMPROVE PRODUCTIVITY: A CASE STUDY IN A MEDIUM SCALE ALUMINIUM COATING INDUSTRY", International Journal of Mechanical Engineering and Technology (IJMET), vol. 8, no. 12 , pp. 800-816, 2017.

[10] T. R. Abo-Alhol, M. Y. Ismail, S. M. Sapuan and M. M. Hamdan, "The Effectiveness of Quality Circle Participation in Industrial and Service Organizations in Malaysia," Journal of Social Sciences 1, no. 1, pp. 25-30, 2005.

[11] D. M. L. Urubio, "The Effects of Quality Control Circle on Employee Perceptions and Attitudes in Selected Companies: Kingdom of Bahrain," International Advanced Research Journal in Science, Engineering and Technology, vol. 3, no. 1, pp. 113-118, 2016.

[12] Zhu and Y. Li, "QCC in Lumber Industry Timber Production Quality Improvement Application," IEEE 17th International Conference on Industrial Engineering and Engineering Management, vol. 17, pp. 876-880, 2010 